\title{
Do referencial de competência comunicativa intercultural para o seu desenvolvimento na educação básica
}

\author{
Aline Facchini Alexandre \\ José Marcelo Freitas de Luna ${ }^{* *}$
}

\section{Resumo}

A internacionalização das instituições de ensino tem sido defendida como um processo que se volta ao currículo pela perspectiva da educação intercultural. Trata-se de envolver e beneficiar todos, não apenas os estudantes que saíram ou sairão para os chamados programas de intercâmbio. Fundamentado no referencial da internacionalização do currículo, da cidadania global e da competência comunicativa intercultural, discutimos, neste artigo, a infusão dos planos e aulas, na própria escola, de uma disciplina curricular da educação básica. Os resultados apontam para a possibilidade de fomento e desenvolvimento das dimensões flexibilidade comportamental, consciência comunicativa, empatia, respeito ao outro, tolerância à ambiguidade e descoberta de conhecimento.

Palavras-chave: Internacionalização do currículo. Competência comunicativa intercultural. Ensino de línguas. Cidadania global.

\section{Considerações iniciais}

Nos últimos anos, o foco do processo de internacionalização das instituições de ensino tem se voltado para o seu elemento definidor, qual seja, o currículo. Isso porque a mobilidade internacional discente e a docente, embora crescentes, não conseguem abranger todos os estudantes. Seguindo a tendência da Europa e de países como a Austrália, as escolas do mundo inteiro preparam-se para o desenvolvimento de atividades chamadas de internacionalização no próprio campus. Trata-se de um processo de reformulação

\footnotetext{
* Graduada em Letras (Português e Inglês). Mestranda em Educação na Universidade do Vale do Itajaí Univali. Professora de Inglês. É membro do grupo do CNPq - Estudos Linguísticos e Ensino de Línguas. E-mail: alinefale@bol.com.br

** Doutor em Linguística pela USP. Professor/Pesquisador do Programa de Pós Graduação em Educação da Univali - Brasil. Professor Visitante da Faculdade de Letras da Universidade de Coimbra - Portugal. É líder do grupo do CNPq - Estudos Linguísticos e Ensino de Línguas. E-mail: mluna@univali.br
}

Data de submissão: set. 2015 - Data de aceite: nov. 2015 http://dx.doi.org/10.5335/rdes.v11i2.5333 
dos currículos dos cursos e das consequentes práticas de ensino e de avaliação.

A exemplo do desenvolvimento científico em geral, a área da internacionalização do currículo, em particular, vem sendo marcado por perguntas como: Por que internacionalizar o currículo? Como elaborar objetivos internacionalizados de aprendizagem? Como usar a diversidade das turmas multiculturais para internacionalizar o currículo? Como desenvolver a avaliação por um currículo internacionalizado? Como estabelecer e manter conexões entre os objetivos de um currículo internacionalizado com as metas institucionais e com as expectativas de aprendizagem dos alunos?

Além de localizar-se interdisciplinarmente, a internacionalização do currículo, segundo Betty Leask, é um processo que deve ser abordado complementarmente pelas políticas e práticas das instituições. Assim, a autora emprega o conceito de currículo para abranger todos os aspectos da situação de ensino e aprendizagem. Critica, portanto, a visão de um currículo como uma lista de tópicos a serem estudados. Para Leask, é a relação entre os três elementos que simultaneamente define o aprendizado e desenvolve as habilidades, o conhecimento e as atitudes necessárias para a sociedade globalizada. Nesse quadro de definições, a internacionalização do currículo é sublinhada como o processo, como o meio de

[...] incorporar dimensões internacionais, interculturais e globais no conteúdo do currículo, bem como nos objetivos de aprendizagem, nas atividades de avaliação, na metodologia, e em todos os serviços voltados a um curso (2015, p. 9).
Trata-se de um processo que demanda o envolvimento fundamentado e o benefício generalizado de/para toda a comunidade acadêmica. Referimo-nos aos gestores, aos professores e aos estudantes eles próprios, que, com uma fundamentação teórico-metodológica própria, devem conceber e desenvolver um currículo internacionalizado sob a perspectiva da educação intercultural. A base, portanto, é a interculturalidade como bem caracteriza Fornet-Betancourt,

[...] interculturalidade quer designar, antes, aquela postura ou disposição pela qual o ser humano se capacita para e se habitua a viver "suas" referências identitárias em relação com os chamados "outros" [...] Não há prática intercultural sem vontade nem exercício de tradução (2004, p. 13-14).

A internacionalização do currículo como área em que se localiza o estudo que, neste artigo, apresentamos, é um processo que envolve todos, não apenas os estudantes que saíram ou sairão para os chamados programas de intercâmbio. A motivação para envolver toda a comunidade escolar no dia a dia de suas atividades de ensino e aprendizagem é que as demandas sociais em geral e do mercado de trabalho em particular são e serão iguais para todos. Pontualmente, as sociedades multiculturais em que vivemos geram situações de comunicação que pressupõem o desenvolvimento de competência comunicativa intercultural (CCI). Para o exercício profissional, os conhecimentos, as atitudes e as habilidades que se requerem são ainda mais reveladoras do quanto que as nossas 
escolas precisam fomentá-los e desenvolvê-los pelo currículo. Para a esfera empresarial, na Europa, por exemplo, o tema é abordado pela relação custo e benefício. Com base em pesquisas, pode-se afirmar que $79 \%$ dos executivos e recrutadores de recursos humanos no Reino Unido afirmam esperar dos candidatos a vagas de suas empresas maior conhecimento e sensibilidade da diversidade do mundo. Preocupadas com fracassos na comunicação intercultural, alegadamente geradores de alto custo, mais de $60 \%$ das empresas provêm seus empregados de treinamento intercultural, alguns desenvolvidos em parceria com centros de pesquisa e universidades.

Por vezes, são as empresas, isoladamente, que preenchem as chamadas lacunas de conhecimento intercultural. Isso ocorre em razão de a escola não conceber tampouco desenvolver um currículo que aborde as salas, seus ocupantes, como multiculturais. Sustentam essa afirmação Moreira e Candau, que dizem:

A escola sempre teve dificuldade em lidar com a pluralidade. Tende a silenciá-la e neutralizá-la. Sente-se mais confortável com a homogeneização e a padronização. No entanto, abrir espaços para a diversidade, a diferença e para o cruzamento de culturas constitui o grande desafio que está chamada a enfrentar (2003, p. 161).

Embora, tradicionalmente, a escola e o mercado não costumem concordar em relação ao currículo que qualifica os jovens para a carreira profissional, são as salas de aula e toda a ambiência escolar que abrigam potencialmente situações que visam ao fomento e ao desenvolvimento da CCI. A propósito, como descrito em Luna, Alexandre e Schaeffer (2015), tal tema e objetivo marcaram exatamente o Fórum Juventude Europa - Lusofonia. Ocorrido em maio de 2014, na Faculdade de Letras da Universidade de Coimbra, em Portugal, o evento reuniu estudantes e profissionais, a maioria deles professores, de Angola, do Brasil e do país sede. Com efeito, a escolha de Portugal para sediar o fórum reflete, na lusofonia, os fatos de um país marcado por fluxos migratórios. Esse processo tem raízes históricas e práticas muito atuais; suas causas e implicações são questões políticas e econômico-sociais, que representam verdadeiros problemas para as escolas e universidades. Sintomaticamente, o Conselho Científico Pedagógico da Formação Contínua de Portugal já há algum tempo fomenta a formação de professores sobre uma base internacional e intercultural. Evidenciam essa experiência alguns programas como os citados a seguir:

a) O professor de línguas estrangeiras: um mediador cultural.

$\rightarrow$ Comunicar na diferença - métodos aumentativos e alternativos de comunicação.

b) Língua Portuguesa e integração na comunidade de acolhimento.

c) Eu e os outros.

d) Educar para a diversidade linguística e cultural. 
Boa parte desses estudos e trabalhos orienta-se pela noção de cidadania global e pelo consequente perfil do cidadão global, assim expresso pela Oxfam:

a) está ciente da amplitude do mundo e do seu papel como cidadão;

b) respeita e valoriza a diversidade;

c) tem uma compreensão acerca de como o mundo opera em termos econômicos, políticos, sociais, culturais, tecnológicos e ambientais;

d) indigna-se com a injustiça social;

e) participa e contribui com a comunidade em nível local e global;

f) deseja agir para fazer o mundo mais sustentável; e

g) assume responsabilidade por suas ações (2006, p. 3).

O conceito de cidadania global deve ser tratado de forma cuidadosa. Isso porque se trata de um termo que gera interpretações variadas, inclusive algumas prejudiciais, como aquelas que se associam a uma cultura e a uma língua dominantes. Leask revela a sua comunhão com outros autores que vêm se referindo à cidadania global responsável. Ao chamar pela 'responsabilidade', o currículo transcende o estágio do 'pensar...' para o 'agir global e localmente'. É assim que o conceito de competência intercultural se apresenta. A contribuição de Leask a esse respeito consiste no alerta de que a competência intercultural é um estado de 'tornar-se', ou seja, os estudantes entram, pelo processo de internacionalização do currículo, em um "estado de tornar-se competente interculturalmente" (2015, p. 63).
Expressamente, a internacionalização do currículo sob a perspectiva da educação intercultural está para desenvolver no estudante um perfil profissiográfico de engajado com a sua comunidade local e com a global. Assim referindo, reproduzimos os princípios de uma pedagogia crítica, traduzida por diretivas do tipo "pensar local e agir globalmente". Isso implica criticar a homogeneização e a ocidentalização nas suas consequentes manutenções e reforços de privilégios de grupos e línguas dominantes. Sobre essa base, os professores podem contemplar, nos seus currículos e planos de ensino e nas aulas elas próprias, os paradigmas marginalizados, devendo, para isso, adotar perspectivas de escolas, autores, culturas e línguas as mais diversas.

As referências que temos, introdutoriamente, feito à CCI já nos permitem afirmar que os planos e as aulas das diversas disciplinas curriculares podem ser infundidos da perspectiva intercultural. Assim orientados, neste artigo, discutimos, em duas seções, os procedimentos teórico-metodológicos da competência comunicativa intercultural para uma aula de língua inglesa da educação básica.

\section{Sobre o referencial}

É principalmente por meio da língua que a cultura de um povo é difundida e reconhecida. A língua falada por determinado grupo social representa a identidade cultural daquele grupo, sendo fator 
determinante que o distingue de outros grupos culturais e identidades. Sobre isso, Hanna afirma que:

Toda sociedade humana tem seus próprios traços, seus próprios intuitos, seus próprios significados, a língua preserva a história e as tradições daquela sociedade por meio dos entendimentos dos significados mais comuns que as pessoas têm das palavras, das expressões e do texto (2012, p. 83).

Não se pode conceber o ensino e a aprendizagem de uma língua estrangeira, no contexto atual, desconsiderando o binômio língua-cultura. Entendemos, assim como Hanna, o ensino de línguas como "um meio de comunicação e interação com pessoas de outra cultura e sociedade" (2012, p. 83-84) e não somente como um conjunto de regras gramaticais a serem memorizadas e, muitas vezes, esquecidas pelos seus aprendizes. Ao destacar a importância no contexto cultural do ensino de línguas, atribuímos importância também ao uso que se faz das coisas, aquilo que se diz, que se pensa e que se sente sobre elas, e se confere às significações de acordo com o contexto em que se está inserido (HANNA, 2012).

A relevância da interculturalidade na prática pedalinguística, apresentada no Quadro Comum de Referências para Línguas (QECR), teve e tem grande importância para o ensino de línguas, pelo lugar da interculturalidade na prática docente. Uma das finalidades principais do QECR é "proporcionar uma base comum para a elaboração de programas de ensino de línguas, bases curriculares, exames e livros-texto em toda a Europa" (CONSELHO DA EUROPA, 2001, p. 1).
Para tal, o documento defende a ideia de que os alunos precisam utilizar a língua para fins comunicativos e foca, principalmente, nos conhecimentos próprios e nas competências necessárias ao desenvolvimento da competência comunicativa e dos princípios do plurilinguismo. Segundo o documento:

A competência plurilíngue e pluricultural refere-se à habilidade de usar línguas para propósitos de comunicação e tomar parte em interação intercultural, onde uma pessoa vista como um agente social tem proficiência, de níveis variados, em diversas línguas e experiência de diversas culturas (CONSELHO DA EUROPA, 2001, p. 168).

Ao motivarmos a experiência de diferentes culturas no ensino e aprendizagem de língua inglesa, reduzimos o risco de considerar o falante nativo como modelo e padrão ideal a ser seguido, e com isso, reduzirmos estereótipos ao valorizar outras identidades.

A dimensão intercultural no ensino de línguas objetiva desenvolver aprendizes como falantes interculturais ou mediadores. $\mathrm{O}$ falante ou mediador intercultural, segundo Byram, Gribkova e Starkey, caracteriza-se como alguém capaz de relacionar-se com múltiplas identidades e evitar estereótipos ao considerar somente uma identidade social; ele é capaz e disposto a (re)descobrir e respeitar as diferenças do outro. Esse movimento, qual seja, de uma cultura para outra, de uma identidade a outra que caracteriza o aprendiz intercultural (destaque feito por Hanna, 2013), implica a consciência da própria cultura do aprendiz e de como 
é percebido pelos outros (HANNA, 2013). Sobre o ensino de línguas sob a dimensão intercultural, é entendido por Byram, Gribkova e Starkey que:

O ensino de línguas sob uma dimensão intercultural busca contribuir para que os aprendizes adquiram a competência linguística que precisam para comunicar oralmente ou através da escrita de forma apropriada. Mas, é seu objetivo também, desenvolver a competência intercultural, ou seja, a habilidade de assegurar um entendimento conjunto de pessoas de diferentes identidades sociais e a habilidade de interagir com pessoas como seres humanos complexos com múltiplas identidades e sua própria individualidade (2002, p. 9-10).

Muitos estudiosos e pesquisadores de CCI confirmam a dificuldade de definir e avaliar as suas dimensões. Isso ocorre, principalmente, pela complexidade de fatores e questões que envolvem a temática. Deardorff define CCI como

A habilidade para comunicar corretamente e de forma bem sucedida em situações interculturais baseado nas habilidades, atitudes e conhecimentos interculturais dos sujeitos (2009, p. 247, tradução nossa).

Leask aponta vários questionamentos relevantes acerca dessa definição, afirmando que apresenta mais indagações do que respostas, como:

Qual critério julgamos efetivo e adequado em relação à CCI: em termos instrumentais (exemplo: é atingido o resultado desejado para ambos naquele momento) ou em termos afetivos (exemplo: é bom para ambos)? Uma interação deve ser bem sucedida e adequada? O que se entende por eficácia nesta situação? É possível ser 'interculturalmente competente' em todas as situações? [...] (2015, p. 63, tradução nossa).
As questões apontadas que remetem à complexidade da CCI, também, caracterizam-na como um processo de construção contínua e permanente e não como algo pronto e acabado. Sobre isso, Leask diz que sendo a CCI um processo contínuo, exige que o indivíduo apresente habilidades, conhecimentos e atitudes, caracterizando-se como "[...] um estado de transformação ao invés de um destino" (2015, p. 63 , tradução nossa).

Assim como Leaks, Byram (1997) também destaca a importância do conhecimento, das habilidades e atitudes no processo de aquisição da CCI. Sobre o conhecimento, Byram afirma que independentemente do nível linguístico que uma pessoa possui, ao interagir com um sujeito de outro país, ela traz consigo conhecimentos prévios que podem influenciar na interação. Segundo Byram:

O conhecimento que os indivíduos trazem para a interação com alguém de outro país pode ser descrito de duas maneiras: conhecimento sobre os grupos sociais e suas culturas em seu próprio país, ou conhecimento semelhante do país de seu interlocutor; e ainda, conhecimento do processo de interação no nível social e individual. A primeira categoria é conhecimento que pode ser mais ou menos refinada, mas sempre presente de algum nível, enquanto a segunda, envolvendo conhecimento sobre conceitos e processos de interação é fundamental para o sucesso da interação, mas não é adquirida automaticamente (1997, p. 35, tradução nossa).

Sobre o papel das atitudes, Byram explica que: 
Elas precisam ser atitudes de abertura de prontidão para suspender descrença e julgamentos a respeito dos significados, crenças e comportamentos dos outros. Deve haver também a motivação para suspender crença nos próprios significados e comportamentos e analisá-los do ponto de vista do outro com o qual o sujeito está interagindo (1997, p. 37, tradução nossa).

Essa condição refere-se a sujeitos que interagem com outros culturalmente diferentes de si. Sobre as habilidades, o mesmo autor afirma que o sujeito deve basear-se em seu conhecimento próprio para, a partir disso, desenvolver atitudes de sensibilidade e compreensão interpessoal. Ao estabelecer relações e mediar possíveis desentendimentos e dificuldades, caracterizamos o falante intercultural.

Para facilitar o entendimento das habilidades, conhecimento e atitudes discutidas, Byram (1997), em conjunto com outros pesquisadores europeus, estabeleceu seis dimensões para avaliação da CCI: Tolerância à ambiguidade, a habilidade para aceitar situações ambíguas e saber lidar com elas; Flexibilidade comportamental, a habilidade de adaptar o comportamento do próprio indivíduo a situações culturais diferentes das suas; Consciência comunicativa, a habilidade de relacionar componentes linguísticos com conteúdos culturais e lidar conscientemente em diferentes contextos culturais; Descoberta de conhecimento, a habilidade de adquirir novo conhecimento de cultura e utilizá-lo, juntamente com habilidades e atitudes, na interação entre diversas culturas; Respeito ao ou- tro, a habilidade de respeitar a cultura do outro, desconstruindo estereótipos da cultura estrangeira e a pretensão de que somente a cultura do próprio indivíduo é válida; Empatia, a habilidade de entender o que os outros pensam e sentem, de posicionar-se no lugar do outros em situações concretas.

Mas como formar cidadãos interculturalmente competentes abertos e sensíveis ao outro? Leask afirma que "[...] é extremamente importante explorar pedagogias que ajudarão o aluno a tornar-se competente interculturalmente" (2015, p. 33, tradução nossa). Byram (1997) aponta a aula de língua inglesa como uma grande oportunidade para o desenvolvimento da CCI, como sendo o momento em que o professor, estando presente, pode levar seus alunos a refletir sobre suas atitudes e conhecimentos. Essa atitude, se bem intermediada pelo professor, deve transcender as paredes da sala de aula.

Entretanto, o professor deve preparar-se para não provocar o inverso em seus alunos, ensinando visões estereotipadas sobre a cultura do outro. Hanna nos diz que:

Incluir cultura nas aulas de língua não significa apenas ensinar como as coisas são ou têm sido, mas como poderiam ser, no sentido de que os aprendizes devem estar atentos para imaginar culturas diferentes das deles. Assim, pode-se evitar que a identidade cultural de um grupo seja vista pelos aprendizes de uma língua estrangeira de maneira estereotipada, já que a percepção do indivíduo a respeito da identidade social do outro está diretamente ligada à maneira como interpreta sua própria cultura (2012, p. 85). 
Um exemplo de uma iniciativa de educação voltada ao desenvolvimento da CCI e ao desenvolvimento da cidadania global é o currículo apresentado pela Oxfam (2006). O projeto tem o objetivo principal de promover um currículo para a cidadania global, preocupado em promover uma educação para crianças e jovens, que desenvolva o pensamento crítico sobre os assuntos globais, que encoraje o respeito ao outro e a responsabilidade para como o mundo como a consciência para as questões ambientais e a responsabilidade para com os outros. Oxfam (2006) apresenta ainda sugestões de atividades para professores e alunos voltados à cidadania global. Uma delas é a exploração de imagens e/ou fotografias associadas a discussões que buscam despertar nos alunos atitudes positivas diante de outras culturas e de sua própria, desenvolvendo empatia e respeito por meio de questionamentos. Segundo o documento da Oxfam:

As fotografias têm um importante papel na formação de atitudes com outras pessoas, culturas e lugares. Elas podem ser utilizadas com grande efeito mesmo com crianças pequenas, para motivar questões, desafiar estereótipos, construir empatia e desenvolver respeito pela cultura da própria criança e da dos outros (2006, p. 10, tradução nossa).

Citamos algumas das sugestões de atividades com fotografias apresentadas pela Oxfam:

a) Modificando situações: olhando cuidadosamente para uma fotografia, discuta com as crianças o que elas acham que está acontecendo. Depois, encoraje-as a utilizar evi- dências da fotografia, levando-as a pensarem sobre o que pode ter acontecido antes e depois de a fotografia ser tirada. Encoraje-as a justificar o que dizem.

b) Além da moldura: cole uma fotografia no meio de uma folha de papel grande. Olhe atentamente para a fotografia e pergunte o que há nela. O que está além de suas bordas. Depois de uma discussão, cada criança no grupo pode ajudar a desenhar no papel ao redor da imagem o que o grupo concorda haver além da moldura.

c) Colocando-se na gravura: observe atentamente uma figura e discuta com as crianças. Permita que as crianças façam desenhos de si mesmas e adicionem à fotografia. Converse sobre as semelhanças entre elas e as pessoas da fotografia.

d) Ligações e semelhanças: mostre para as crianças a figura de alguém de outro país. Peça a elas para pensarem nas ligações e semelhanças entre as suas vidas e a da pessoa na figura (2006, p. 10, tradução nossa).

O exemplo da atividade mostrada oferece subsídios que permitem que o professor desenvolva a CCI em seus alunos, pois apresenta a possibilidade de trabalhar com as seis dimensões necessárias ao seu desenvolvimento: consciência comunicativa, tolerância à ambiguidade, respeito ao outro, empatia, flexibilidade comportamental e descoberta de conhecimento. 
Entretanto, para que o professor o faça, é necessário que ele esteja consciente da importância de formar cidadãos interculturais e que, acima de tudo, saiba como fazê-lo. Branco (2011) defende uma educação que prepare primeiramente os professores a lidar com a alteridade e com sua própria individualidade e identidade, para então serem capazes de ensinar essas habilidades a seus alunos. Bizarro e Braga contribuem, afirmando que:

No século XXI, um professor precisa saber identificar e distinguir os conceitos e atitudes, valores, crenças e comportamentos. Precisa identificar, caracterizar e desmontar estereótipos culturais. Precisa, ainda, de, assumindo um ponto de vista humanista, pedagógico e cientificamente competente, se servir de formas e meios diversos de comunicação para anular preconceitos, recorrendo a estratégias educativas variadas e a metodologias que sirvam o conhecimento do EU e do OUTRO (2004, p. 63, grifo do autor).

Alguns desafios para a promoção de uma educação intercultural, que respeite e promova os direitos humanos e articule questões relativas à igualdade e à diferença, foram identificados e agrupados por Candau:

$\checkmark \mathrm{O}$ primeiro desafio está relacionado à necessidade de desconstrução. Para a promoção de uma educação intercultural é necessário penetrar no universo de preconceitos e discriminações que impregna - muitas vezes com caráter difuso, fluido e sutil todas as relações sociais que configuram os contextos educacionais. Outro aspecto imprescindível é questionar o caráter monocultural e etnocentrismo que, explicita ou implicitamente, estão presentes na escola e nas políticas educativas e impregnam os currículos escolares.

$\checkmark$ Um segundo núcleo de preocupações relacionadas à articulação entre igualdade e diferença no nível das políticas educativas, assim como nas práticas pedagógicas. Essa preocupação supõe o reconhecimento e a valorização das diferenças culturais, dos diversos saberes e práticas e a afirmação de sua relação com o direito à educação para todos; $\checkmark \mathrm{O}$ terceiro desafio vincula-se ao resgate dos processos de construção das identidades culturais, tanto no nível pessoal como coletivo. Deve ser dada especial atenção aos aspectos relativos à hibridização cultural e à constituição de novas identidades culturais; $\checkmark$ Um último núcleo tem como eixo fundamental promover experiências de interação sistemática com os "outros": para sermos capazes de relativizar nossa própria maneira de situar-nos diante do mundo e atribuir-lhe sentido, é necessário que experimentemos uma intensa interação com os diferentes modos de viver e expressar-se (2003 apud Candau, 2008, p. 53-54).

A formação e a requalificação de educadores, com vistas à superação da visão monocultural e etnocêntrica, configura-se, de acordo com Nanni (1997) apud Fleuri (2001) se não o maior, um dos maiores desafios ao sucesso ou ao fracasso da proposta intercultural. A superação da visão monocultural e etnocêntrica dos educadores, que se caracteriza como reforçadora de estereótipos culturais, racismo, sexismo, etc., configura-se como um desafio a ser superado.

Há urgência de políticas e currículos que criem as condições necessárias para aproximar as minorias étnico-sociais e o outro do currículo no programa escolar educativo. Segundo Almeida (2010), o Estado tem a urgência de criar tais condições, e, sobretudo, é oportunizando as diferentes heranças culturais no ambiente escolar que verdadeiramente a voz da democracia se fará ouvida. 
Diante disso, o entendimento e a discussão da educação intercultural ganha cada vez mais importância no cotidiano educativo e faz-se indispensável, configurando-se como um dos desafios contemporâneos ao trabalho docente.

A seguir, apresentaremos a simulação de uma atividade de língua inglesa para aluno do 6 ano do ensino fundamental, voltada ao desenvolvimento da CCI, utilizando as seis dimensões da CCI.

\section{Simulação de uma atividade de inglês sobre o desenvolvimento da competência comunicativa intercultural}

Apresentamos a simulação de uma aula de Língua Inglesa preparada para alunos da educação básica de uma escola brasileira. É pertinente mencionar que esses alunos têm aulas de inglês uma vez por semana, e muitos deles já estudam a língua e os aspectos relacionados a ela desde o $1^{\circ}$ ano do ensino fundamental I. A simulação objetiva utilizar as seis dimensões da CCI com o propósito de desenvolvê-las.

Como sugerido pela Oxfam (2006), o uso de imagens ou fotografias associadas a estratégias e questionamentos que levem o aluno a ver a si e ao outro de forma crítica é pertinente. Desta feita, utilizamos, como estratégia inicial, imagem selecionada do livro FTD sistema de ensino: inglês $6^{\circ}-$ ano, das autoras
Mariana Killner e Rosana Gemima Amancio.

Figura 1: This is my friend Sarah!

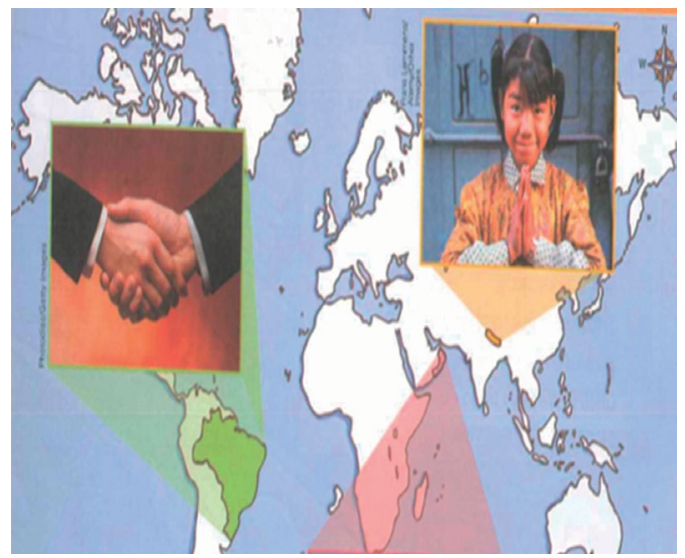

Fonte: Killner e Amancio (2010, p. 3).

Primeiramente, as crianças olham atentamente a imagem. Em seguida, o professor faz as seguintes perguntas:

a) Em sua opinião, o que as pessoas apresentadas na fotografia estão fazendo?

b) Por que elas fazem isso de maneira diferente? $\mathrm{O}$ que as ajudou a chegar a essa conclusão?

c) Em nosso país, as pessoas também se cumprimentam de maneiras diferentes? Cite uma maneira, em nosso país, de se cumprimentar alguém que você conhece.

d) Existem maneiras formais e informais de cumprimentar as pessoas. Explique duas situações distintas e como devemos nos comportar.

Depois da discussão inicial promovida pelas questões apresentadas e mediadas 
pelo professor, em duplas, as crianças apresentam uma pequena encenação, cujo objetivo é apresentar-se em inglês, utilizando formas de cumprimentos (formais, informais, de diferentes países ou de seu próprio país).

Ao final das dramatizações, os alunos respondem às seguintes perguntas:

1) Como você se sentiu ao realizar a atividade?

2) O que você aprendeu ou descobriu?

Das atividades citadas, podemos constatar a emergência das seis dimensões de CCI: Descoberta de conhecimento, Empatia, Respeito ao outro, Consciência comunicativa, Tolerância à ambiguidade e Flexibilidade comportamental.

Quando questionado sobre "o que as pessoas nas fotografias estão fazendo”, o aluno 01 responde:

Se cumprimentando, e como cada país tem a sua cultura, as pessoas fazem isso de maneiras diferentes (dados da pesquisa, aluno 01).

Como se pode depreender da resposta do aluno 01, percebe-se que, dependendo da cultura em que uma pessoa está inserida, ela deverá comportar-se de uma maneira distinta, neste caso, cumprimentando. Ao descobrir isso, o aluno 01 mostra habilidade para adquirir um novo conhecimento de cultura, visto que se mostra consciente das diferenças culturais. Sobre isso, Byram (1997) nos diz que a dimensão Descoberta de conhecimento é a habilidade de adquirir novo conhecimento de cultura e utilizá-lo, juntamente com habilidades e atitudes, na interação entre diversas culturas.

$\mathrm{Na}$ segunda questão, "Por que elas fazem isso de maneira diferente? $\mathrm{O}$ que o ajudou a chegar a essa conclusão?”, Os alunos respondem:

Do mesmo jeito que as pessoas se vestem diferente, agem diferente e falam outras línguas (dados da pesquisa, aluno 02).

Ao caracterizar que as pessoas se cumprimentam de maneiras diferentes, do mesmo jeito que se vestem, agem e falam, o aluno 02 mostra respeito à cultura do outro. O aluno 02 não critica e não valoriza a maneira de cumprimentar, mas reconhece positivamente outras manifestações culturais. A dimensão Respeito ao outro é explicada por Byram (1997) como a habilidade de respeitar a cultura do outro, desconstruindo estereótipos da cultura estrangeira e a pretensão de que somente a cultura do próprio indivíduo é válida.

Pode ser por causa da cultura, mas pode ser também porque cada pessoa tem a sua característica (dados da pesquisa, aluno 03).

No extrato citado, o aluno 03 mostra habilidade para posicionar-se no lugar do outro ao identificar que as pessoas cumprimentam-se de maneira diferente porque são distintas umas das outras, mesmo pertencendo à mesma cultura. Byram (1997) identifica a dimensão Empatia como a habilidade de entender o que os outros pensam e sentem, de posicionar-se no lugar do outro em situações concretas. 
Para a questão 3, "Em nosso país, as pessoas também se cumprimentam de maneiras diferentes? Cite uma maneira, de se cumprimentar alguém que você conhece", têm-se alguns extratos:

Dar um tapinha nas costas do colega é para cumprimentar alguém que a gente conhece (dados da pesquisa, aluno 04).

Ao responder que dar uma tapinha nas costas é uma forma de cumprimentar alguém que se conhece, o aluno 04 mostra habilidade para adaptar seu comportamento a outras situações de interação. Essa habilidade pode ser identificada pela dimensão Flexibilidade comportamental. Byram (1997) nos diz que flexibilidade comportamental é habilidade de adaptar o comportamento do próprio indivíduo em situações culturais diferentes das suas.

$\mathrm{Na}$ questão 04, quando questionados "Existem maneiras formais e informais de cumprimentar as pessoas. Explique duas situações distintas e como devemos nos comportar". Os alunos respondem:

Não intimas: boa tarde, bom dia (dados da pesquisa, aluno 05).

Quando eu vou falar com meu amigo, é uma situação informal, quando eu vou falar com o diretor é formal (dados da pesquisa, aluno 06).

Nessas respostas, percebemos que os alunos 05 e 06 identificam o que é uma situação formal ou informal e que, dependendo do tipo de interação e contexto cultural, terão de utilizar formas apropriadas de cumprimento. Sobre isso, Byram (1997) nos diz que a Consciência comunicativa pode ser entendida como a habilidade de relacionar componentes linguísticos aos conteúdos culturais e lidar conscientemente em diferentes contextos. É pertinente mencionar que ao referir "diferentes contextos culturais" não tratamos apenas de outros países, mas das variações culturais existentes em nosso próprio contexto social. Desta feita, ao identificar maneiras formais e informais de cumprimentos, os estudantes devem mostrar habilidade de posicionar-se diante de diferentes contextos.

A atividade proposta, dramatização, faz emergir as seis dimensões de CCI. Segundo Byram (1997), a Empatia pode ser entendida como a habilidade de entender o que os outros pensam e sentem e de se posicionar no lugar do outros em situações concretas. Ao escolher que tipo de cumprimento usar, a pessoa deverá mostrar habilidade para colocar-se no lugar do outro em situações concretas. A dimensão Respeito ao outro também se identifica com essa situação, pois ao escolher outra cultura para representar ou a sua própria, o sujeito deve, de acordo com Byram (1997), mostrar habilidade de respeitar a cultura do outro, desconstruindo estereótipos da cultura estrangeira e a pretensão de que somente a cultura do próprio indivíduo é válida. A consciência comunicativa irá emergir na escolha do tipo de interação (formal, informal, que linguagem corporal, oral, etc.). A dimensão Tolerância à ambiguidade é entendida por Byram 
(1997) como a habilidade para aceitar situações ambíguas e saber lidar com elas. Ora, ao cumprimentar alguém de uma maneira diferente da sua, $o$ aluno encontra-se em uma situação adversa a sua. A flexibilidade comportamental também é percebida, pois os alunos terão que interagir e utilizar códigos não comuns a sua cultura. A dimensão Descoberta de conhecimento também é percebida, visto que os alunos deverão mostrar conhecimento sobre outras culturas para escolher qual irão representar.

Com a última atividade, as duas questões que cada aluno escreve sobre impressões que teve das atividades desenvolvidas, o professor recebe a devolutiva do que seus alunos apreenderam ou não e quais dimensões poderão ser mais exploradas em outras atividades. Essa atividade é uma importante ferramenta, e pode revelar muito para o professor, se ele estiver instrumentalizado a reconhecer as dimensões de CCI e as habilidades necessárias para formar cidadãos globais. Citamos alguns extratos:

Me senti muito bem por aprender culturas diferentes (questão 1, aluno 07).

Por este extrato, o aluno 07 mostra a habilidade para adquirir conhecimento sobre outras culturas, e empatia, quando afirma sentir-se bem.

Eu descobri vários tipos de comprimentos e descobri como eu posso fazer (questão 2, aluno 08),

$\mathrm{O}$ aluno 08 descobre outras formas de cumprimentos. Mostra, com isso, a dimensão Descoberta de conhecimento, como já destacada por Byram (1997). Mostra, também, flexibilidade comportamental, pois está disposto a adaptar sua forma de cumprimentar conforme 0 contexto cultural.

Eu me senti como se estivesse na China me cumprimentando com os habitantes daquele país (questão 1, aluno 09)

Nessa resposta, percebemos que o aluno 09 mostra empatia e respeito ao outro, pois se dispõe a colocar-se no lugar do outro, respeitando sua cultura e a do outro.

\section{Considerações finais}

Cientes da importância de difundir e vivenciar um currículo voltado à educação intercultural em nossas escolas, apresentamos a simulação de uma atividade que pretende discutir os procedimentos teórico-metodológicos da CCI para uma aula de língua inglesa da educação básica.

Seja pelos movimentos de globalização, que marcaram, e marcam, a necessidade de comunicação e interação com outras culturas ou pela realidade multicultural que encontramos em nossa própria sociedade, o trabalho da educação intercultural com discentes torna-se cada vez mais urgente.

Com o objetivo de apresentar a simulação de uma atividade que apresente as seis dimensões de CCI, quais sejam: Flexibilidade comportamental, Consciência comunicativa, Empatia, Respeito 
ao outro, Tolerância à ambiguidade e Descoberta de conhecimento, discutimos brevemente os achados da pesquisa.

Evidenciamos que, pelo desenvolvimento da CCI, têm-se muitos benefícios, como a superação de processos marcados pela evidência dos diferentes e diferenças e com isso, a busca por relações de abertura e compreensão em relação ao Outro. Os achados relevam que os alunos que participaram da atividade vivenciaram situações de abertura ao Outro e desenvolvimento de CCI através das dimensões: descoberta de Conhecimento, quando o Aluno 01 descobre que dependendo da cultura em que está inserido deve comportar-se de maneira distinta; consciência comunicativa, quando os Alunos 05 e 06 identificam que dependendo do tipo de interação deverão utilizar-se de cumprimentos mais formais ou informais; empatia, quando o Aluno 03 identifica que cada pessoa, independentemente de sua cultura, tem características próprias que devem ser respeitadas; respeito ao Outro, quando o Aluno 09 diz "sentir-se na China", mostrando habilidade para colocar-se no lugar do outro; flexibilidade Comportamental, quando o Aluno 04 mostra-se disposto a adaptar seu comportamento às diferentes formas de formalidade ao cumprimentar-se; e tolerância à ambiguidade, evidenciada muito bem durante a simulação e nos depoimentos de todos os alunos em resposta as questões 01 e 02 , no final da atividade, quando os alunos respondem ter apreciado a experiência, sentindo-se à vontade durante a dramatização. A atividade mostra-se, portanto, apropriada para o desenvolvimento das dimensões de CCI.

Ainda sobre o desenvolvimento de CCI, destacamos, assim como Leask (2015) e Fantini (2009) o fazem, que se caracteriza como um processo longitudinal e contínuo, não sendo um instrumento ou uma atividade isoladamente aplicada, suficiente para desenvolver a consciência comunicativa intercultural nos discentes, mas, sim, um currículo internacionalizado sob a perspectiva da educação intercultural.

Um currículo internacionalizado, que perpasse a educação básica e superior com vistas à educação intercultural, demanda a incorporação de uma perspectiva global aos objetivos de aprendizagem, ao conteúdo programático, aos recursos instrucionais, às práticas de ensino e às avaliações de disciplinas de cursos (LUNA, ALEXANDRE e SCHAEFFER, 2015). É um processo contínuo, que deve ser buscado e incentivado, se pretendemos desenvolver cidadãos abertos ao outro, e a escola, principalmente, na educação básica, é o lugar onde tudo começa.

\section{The framework of Intercultural} Communicative Competence for its development in the basic education classroom

\begin{abstract}
The internationalization of educational institutions has been supported as a process that turns the curriculum from the perspective of intercul-
\end{abstract}


tural education. It is a process that involves and benefits everyone, not just students who have left or will leave for so-called exchange programs. Based on the internationalization of curriculum framework, global citizenship and intercultural communicative competence, we have discussed in this article the infusion of plans and classes at school, in a basic education curriculum discipline. The results show the possibility of promotion and development of the Behavioral Flexibility, Communicative Awareness, Empathy, Respect for the Other, Tolerance Ambiguity and Knowledge Discovery dimensions.

Keywords: Internationalization of Curriculum. Intercultural Communicative Competence. Language Teaching. Global citizenship.

\section{Referências}

ALMEIDA, V. M. de. O mediador sócio-cultural em contexto escolar - Contribuições para a compreensão da sua função social. Portugal: Pedagogo, 2010.

BRANCO, D. M. S. A competência intercultural no ensino: proposta para formação contínua de professores do $2^{\circ}$ e $3^{\circ}$ ciclos do ensino básico. 2011. 132f. Dissertação (Mestrado em Português) - Universidade Aberta, Portugal, 2011.

BIZARRO, R.; BRAGA, F. Educação intercultural, competência plurilingue e competência pluricultural: novos desafios para a formação de professores de línguas estrangeiras. Porto: Universidade do Porto, 2004. Disponível em: <http://ler.letras.up.pt/uploads/ficheiros/4373.pdf>. Acesso em: 2 dez. 2014.

BYRAM, M. Teaching and assessing intercultural communicative competence. Philadelphia, PA: Multilingual Matters, 1997.
BYRAM, M.; GRIBKOVA B.; STARKEY, $\mathrm{H}$. Developing the intercultural dimension: language teaching: a practical introduction for teachers. Strasbourg: Council of Europe, 2002.

CANDAU, V. M. Direitos humanos, educação e interculturalidade: as tensões entre igualdade e diferença. Revista Brasileira de Educação, Rio de Janeiro, n. 37, p. 45-56, jan./abr. 2008.

CONSELHO DA EUROPA. Quadro europeu comum de referência para as línguas: aprendizagem, ensino, avaliação. Porto: Asa, 2001. (Coleção Perspectivas Actuais/Educação).

DEARDORFF, D. K. The SAGE handbook of intercultural competence. Thousands Oaks, CA: Sage, 2009.

FANTINI, Alvino. E. Assessing Intercultural Competence. In: DEARDORFF, D. K. The SAGE Handbook of Intercultural Competence. Thousands Oaks, CA: Sage, 2009. p. 456-476.

FLEURI, R. M. Desafios à educação intercultural no Brasil. Educação, Sociedade e Culturas, Porto, n. 16, p. 45-62, 2001.

FORNET-BETANCOURT, R. Interculturalidade: crítica, diálogo e perspectiva. São Leopoldo: Nova Harmonia, 2004.

HANNA. V. L. H. Línguas estrangeiras: o ensino em um contexto cultural. São Paulo: Editora Mackenzie, 2012.

KILLNER, M.; AMANCIO, R. G. FTD sistema de ensino: inglês $6^{\circ}$ ano. São Paulo: FTD, 2010.

LEASK, B. Internationalizing the curriculum. London: Routledge Taylor; New York: Francis Group, 2015.

LUNA, J. M. F.; ALEXANDRE, A.; SCHAEFER, R. Uma avaliação da competência comunicativa intercultural de professores lusófonos. Revista Línguas \& Letras, Cascavel, n. 32, p. 336-352, 2015. 
MOREIRA, A. F.; CANDAU, V. M. Educação escolar e cultura/s: construindo caminhos. In: Revista Brasileira de Educação, Rio de Janeiro, n. 23, p. 156-168, maio/jun./jul./ago. 2003.

OXFAM Development Education Program. Education for Global Citizenship: a guide for schools. 2006. Disponível em: <http://www. oxfam.org.uk/education/gc/files/education_ for_global_citizenship_a_guide_for_schools. pdf>. Acesso em: 1 ago. 2015. 